\title{
REAÇÃO ÁLCALI-AGREGADO - TÉCNICAS UTILIZADAS PARA CARACTERIZAÇÃO E IDENTIFICAÇÃO DE PRODUTOS FORMADOS
}

\author{
VALENGA, MATHEUS VILLIAN \\ Graduando \\ Universidade Estadual de Ponta Grossa \\ Paraná; Brasil \\ matheusvillianvalenga1234@gmail.com
}

\author{
FARIAS. MARCELO MIRANDA \\ Engenheiro Civil \\ Universidade Estadual de Ponta Grossa \\ Paraná; Brasil \\ marcelomirfa@gmail.com
}

\author{
PEREIRA. EDUARDO \\ Professor \\ Universidade Estadual de Ponta Grossa \\ Paraná; Brasil \\ eduardopereira@uepg.br
}

\author{
PEREIRA, ELIAS \\ Professor \\ Universidade Estadual de Ponta Grossa \\ Paraná; Brasil \\ elpereira@uepg.br
}

\author{
LIMA, RUBIA CATARINA PRZYBYS \\ Graduando \\ Universidade Estadual de Ponta Grossa \\ Paraná; Brasil \\ rubia_plc_10@hotmail.com
}

\section{RESUMO}

O concreto é um dos materiais de construção mais utilizados em estruturas. Um dos principais fatores estudados e que promove sua deterioração é a reação álcali-agregado (RAA). O objetivo deste trabalho foi analisar a efetividade dos métodos de caracterização de agregados reativos, sendo eles o método químico de reatividade e o método acelerado em barras de argamassa. Foram utilizados 7 agregados diferentes e para cada um, moldadas barras de argamassa para o método acelerado e monitoradas por 60 dias, com posterior análise da estrutura por MEV e análise da redução de alcalinidade da solução a $1 \mathrm{~N}$ de $\mathrm{NaOH}$ do método químico após 24 horas de imersão. Verificou-se que os ensaios de alcalinidade analisados de forma isolada não são suficientes para classificação da reatividade dos agregados. Por outro lado, o período de 60 dias de análises no ensaio acelerado associado com análises de microestrutura foram métodos eficazes para o estudo destas reações.

Palavras-chave: cocreto; durabilidade; reação álcali-agregado.

\section{ABSTRACT}

Concrete is one of the most commonly used building materials in structures. One of the main factors studied that promotes its deterioration is the alkali-aggregate reaction (RAA). The objective of this work was to analyze the effectiveness of the reactive aggregate characterization methods, which are the chemical reactivity method and the accelerated method in mortar bars. Seven different aggregates were used, and molded 3 mortar bars to each one for the accelerated method and monitored for 60 days, with subsequent analysis of the structure by SEM and analysis of the alkalinity reduction of the $1 \mathrm{~N} \mathrm{NaOH}$ solution. chemical method after 24 hours of soaking. The results show that alkalinity assays analyzed alone are not sufficient to classify the reactivity of aggregates. On the other hand, the 60-day accelerated assay period associated with microstructure analyzes were effective methods for studying these reactions. Keywords: concrete; durability; alkali-aggregate reaction. 


\section{INTRODUÇÃO}

Por ser um dos materiais de construção mais utilizados por todo o mundo, o concreto de cimento Portland além de apresentar propriedades mecânicas adequadas para o uso estrutural, também deve apresentar durabilidade para resistir às ações químicas e físicas ambientais e requisitos do projeto. Desse modo, o foco de estudos tem aumentado perante fatores que influenciam a durabilidade do concreto, a fim de melhorar o seu desempenho ou diminuir os efeitos de agentes que prejudicam suas propriedades originais.

A Reação Álcali-agregado (RAA) promove a deterioração do concreto por meio de expansões e fissuras, gerando redução da resistência mecânica e deformações, podendo ocasionar o colapso da estrutura. Isso se deve à formação de um gel higroscópico no interior do concreto que na presença de água expande causando tensões internas nas paredes dos poros, sendo produto das reações entre os álcalis livres $\left(\mathrm{Na}^{+}, \mathrm{K}^{+} \mathrm{e} \mathrm{Ca} \mathrm{Ca}^{+}\right)$dissolvidas nos mesmos, e os minerais dos agregados potencialmente reativos usados na confecção do concreto (SILVA et al., 2010; PEREIRA, E. et al., 2017).

Para que ocorra a RAA é necessário um ambiente que a propicie. Pereira et al. (2018) indicaram que a velocidade e grau de deterioração da estrutura é função de diversas variáveis, como temperatura e a umidade ambiente, reatividade dos agregados e álcalis livres na matriz cimentícia após a cura. Ressalta-se que a água é um fator essencial para que a reação ocorra, funcionando como solução para que os álcalis possam migrar e desencadear a reação (BÉRUBÉ et al., 2002). Os minerais dos agregados contribuem para o desenvolvimento da reação devido sua composição química, sendo os principais a sílica cristalina ou amorfa, opala, calcedônia, cristobalita e tridimita, além de vidros em geral devido sua baixa cristalinidade (SOUZA, ZOLETT, CARRAZEDO, 2016) e de feldspatos alcalinos de potássio ou sódio, agindo como fonte de álcalis para a reação (PEREIRA, 2018).

Apesar do foco dos estudos perante o assunto ter crescido desde suas primeiras manifestações no século passado, ainda não é de completo entendimento dos pesquisadores todos os mecanismos atuantes e produtos das reações devido sua grande complexidade (SHON, 2008). Cenário justificado em parte pela baixa confiabilidade de alguns métodos de caracterização de reatividade dos agregados perante as manifestações da RAA. O ensaio acelerado de barras de argamassa é criticado pelo baixo tempo de exposição das amostras e temperaturas elevadas (BÉRUBÉ, FRENETTE, 1994), já o método químico, apesar de sua popularidade, é criticado quanto a granulometria não abrangente, temperatura e tempo de exposição das amostras, além da cristalinidade dos minerais e suas composições. Com isso, a reação álcaliagregado pode ser considerada uma das grandes problemáticas a ser mitigada pelo desenvolvimento de métodos e estudos científicos, garantindo confiabilidade aos procedimentos de caracterização de agregados (ROLIM, 2010).

Desse modo, o objetivo proposto neste artigo é analisar a efetividade dos métodos químico simples e acelerado de expansão de barras de argamassa para a determinação de agregados deletérios e determinação de fases reativas e de produtos da reação álcali-agregado na estrutura da argamassa por microscopias eletrônica de varredura, indicando se os métodos mencionados apresentam resultados satisfatórios.

\section{MATERIAIS E MÉTODOS}

Para o estudo foram utilizados sete agregados diferentes denominados de: A, B, C, D, E, F e Referência, de diferentes regiões dos Campos Gerais no Paraná e como aglomerante o cimento Portland CP II F - 32. A caracterização física dos agregados foi feita seguindo a normativa NBR 7211 (2009), sendo os ensaios requisitados a distribuição granulométrica (NBR NM 248: 2003), massa específica e massa específica aparente (NBR NM 52: 2009), determinação da absorção de água (NBR NM 30: 2001), massa unitária e volume de vazios (NBR NM 45: 2006) e determinação do material pulverulento por lavagem (NBR NM 46: 2003). Por consequente foi-se realizado o ensaio acelerado das barras de argamassa conforme ASTM C - 1260/07, microscopia eletrônica de varredura em amostras das barras após ensaio acelerado e por fim ensaio químico de reatividade conforme ASTM C - 289/07.

Para a realização da caracterização física dos agregados, foram seguidas as requisições normativas conforme NBR 7211: (2009) e a caracterização química foi realizada por FRX e DRX. A imersão das 4 barras de argamassa de cada agregado do ensaio acelerado foi de 60 dias, aproximadamente quatro vezes maior que o indicado pela ASTM C 1260/07 em solução alcalina de $\mathrm{NaOH}$ na proporção de 1 normal (1N). Para a análise microscópica foram utilizadas amostras das barras rompidas, sendo assim possível observar os produtos formados em sua microestrutura após o período de 60 dias. Para o ensaio químico, as requisições normativas da ASTM C - 289/07 também foram obedecidas, com peneiramento, lavagem e imersão da fração granulométrica específica em solução de $\mathrm{NaOH}$ a $1 \mathrm{~N}$ por 24 horas.

\section{RESULTADOS E DISCUSSÕES}

A caracterização física dos agregados indicou que eles são semelhantes, não apresentando variações consideráveis, com exceção do material de Referência que não se mostrou tão fino quanto os demais. Fato este ligado a origem do mesmo, que é um agregado quartzoso proveniente de leito de rio, enquanto os demais são oriundos de britagem. Os dados da caracterização física dos materiais podem ser observados na Tabela 1. 
Tabela 1 - Caracterização física dos agregados utilizados.

\begin{tabular}{c|c|c|c|c|c|c}
\hline Areia & DMC & MF & Massa Específica Real $\left(\mathrm{g} / \mathrm{cm}^{3}\right)$ & Massa Unitária $\left(\mathrm{g} / \mathrm{cm}^{3}\right)$ & Pulverulento (\%) & Absorção (\%) \\
\hline A & 4,8 & 2,55 & 2,60 & 1,43 & 15,08 & 2,27 \\
\hline B & 2,4 & 2,13 & 2,59 & 1,49 & 13,78 & 2,16 \\
\hline C & 2,4 & 2,59 & 2,60 & 1,41 & 11,46 & 3,71 \\
\hline D & 2,4 & 2,20 & 2,78 & 1,48 & 21,08 & 1,39 \\
\hline E & 2,4 & 2,33 & 2,51 & 1,36 & 12,05 & 5,27 \\
\hline F & 2,4 & 2,46 & 2,93 & 1,71 & 23,65 & 5,27 \\
\hline REF. & 2,4 & 1,94 & 2,63 & 1,62 & 3,62 & 0,64 \\
\hline
\end{tabular}

A caracterização química e mineralógica também demonstrou diversas semelhanças entre os agregados, sendo eles predominantemente constituídos de plagioclásios e feldspatos, além de outros minerais, como filossilicatos e periclase com exceção do agregado de Referência, que é composto majoritariamente por quartzo. Os dados obtidos das caracterizações por DRX e FRX podem ser observados na Tabela 2:

Tabela 2 - Caracterização química e mineralógica dos agregados.

\begin{tabular}{|c|c|c|c|c|c|c|c|c|c|c|c|c|}
\hline \multirow{2}{*}{ Agregado } & \multicolumn{7}{|c|}{ Principais Óxidos (\%) } & \multicolumn{5}{|c|}{ Minerais } \\
\hline & $\mathrm{CO}_{2}$ & $\mathrm{Na}_{2} \mathrm{O}$ & $\mathrm{Al}_{2} \mathrm{O}_{3}$ & $\mathrm{SiO}_{2}$ & $\mathrm{~K}_{2} \mathrm{O}$ & $\mathrm{CaO}$ & $\mathrm{Fe}_{2} \mathrm{O}_{3}$ & Plag. & Felds. & Quartzo & Filos. & Peric. \\
\hline A & 5,52 & 5,40 & 14,30 & 66,00 & 4,58 & 1,26 & 2,51 & $\mathrm{x}$ & - & $\mathrm{x}$ & - & - \\
\hline B & 5,31 & 5,13 & 14,20 & 65,80 & 4,36 & 1,05 & 3,52 & $\mathrm{x}$ & - & $\mathrm{x}$ & - & - \\
\hline $\mathrm{C}$ & 5,15 & 5,02 & 14,60 & 65,90 & 4,71 & 1,18 & 3,08 & $\mathrm{x}$ & - & $\mathrm{x}$ & - & $\mathrm{x}$ \\
\hline $\mathrm{D}$ & 4,87 & 2,99 & 15,00 & 55,90 & 4,14 & 4,32 & 7,64 & $\mathrm{x}$ & - & $\mathrm{x}$ & $\mathrm{x}$ & - \\
\hline $\mathrm{E}$ & 5,22 & 2,12 & 14,40 & 67,20 & 8,04 & 1,05 & 1,63 & - & $\mathrm{x}$ & $\mathrm{x}$ & - & - \\
\hline $\mathrm{F}$ & 6,22 & 2,71 & 14,30 & 45,00 & 1,11 & 9,01 & 14,20 & $\mathrm{x}$ & - & $\mathrm{x}$ & - & $\mathrm{x}$ \\
\hline REF & - & - & 3,16 & 86,27 & 1,45 & - & 2,12 & - & - & $\mathrm{x}$ & - & - \\
\hline
\end{tabular}

Para a interpretação dos dados obtidos do ensaio acelerado das barras, a média das medidas das expansões lineares realizadas foram expostos em uma dispersão para a plotagem de linhas de tendências. Desse modo, são visíveis os comportamentos das amostras ao longo dos 60 dias de execução do ensaio acelerado e pôde-se indicar o potencial reativo dos agregados. O gráfico gerado pode ser observado na Figura 1:

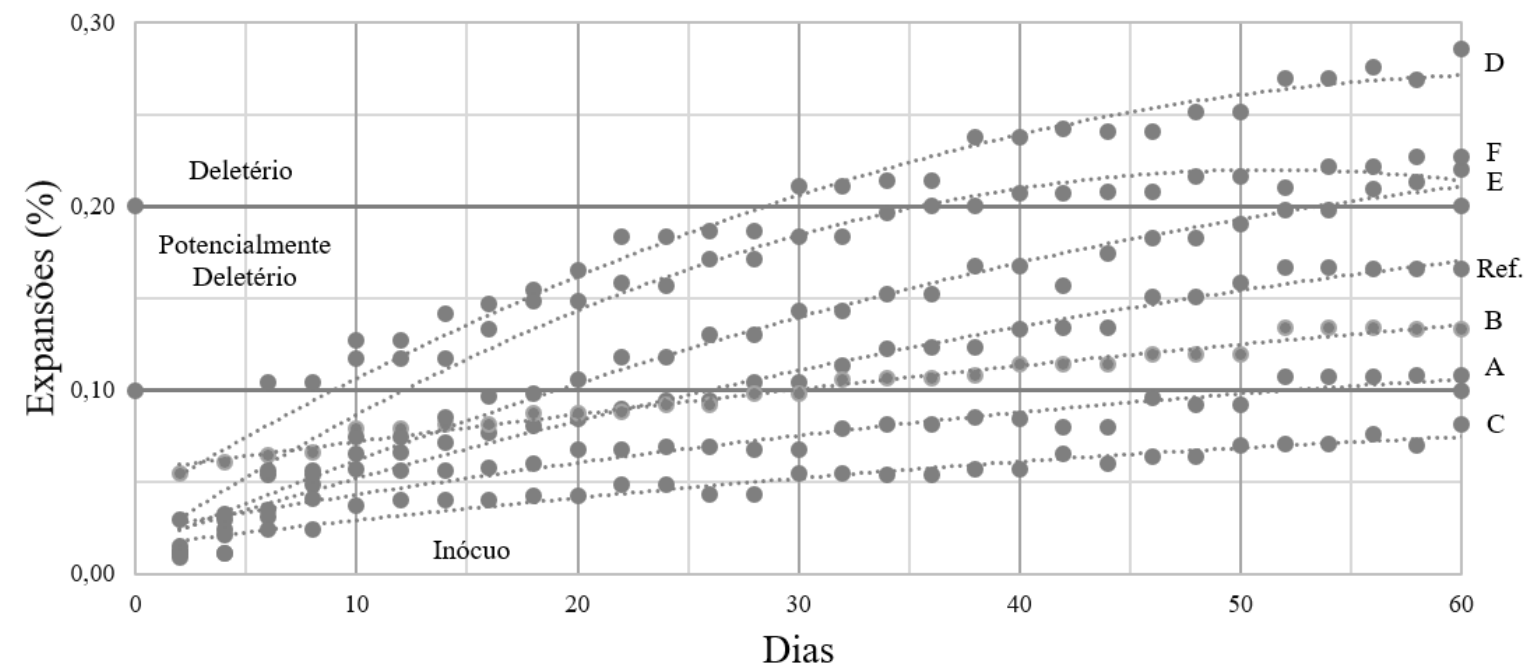

Figura 1: Expansões das barras de argamassa em solução de $\mathrm{NaOH}$ a 1 normal no período de 60 dias.

Pelo gráfico da Figura 1 é possível observar que até os primeiros 16 dias de execução do ensaio, apenas dois agregados são classificados como potencialmente deletérios, sendo eles os agregados D e F. Os demais foram classificados como inócuos nesse periodo, por não terem apresentado expansões lineares maiores que $0,1 \%$ de seu comprimento inicial. Porém a partir desse período até os 28 dias, as barras continuaram expandindo até um cenário onde os agregados $\mathrm{D}$ e $\mathrm{F}$ não eram os únicos classificados como potencialmente deletérios. Nesse estágio, os materiais caracterizados como potencialmente deletérios são os agregados D, E, F e de Referência, onde as expansões podem estar ligadas a reação 
álcali-silicato na microestrutura da argamassa, conhecida por apresentar um desenvolvimento tardio em relação a reação álcali-sílica (VALDUGA, 2002; SHON, 2008).

Já aos 60 dias o cenário se encontra em uma situação consideravelmente crítica. Apenas um agregado ainda é caracterizado como inócuo, sendo ele o agregado C. Os agregados A, B e de Referência são classificados como potencialemente deletérios. Já os agregados D, E e F por apresentarem expansões superiores a $0,2 \%$ são definidos como deletérios sendo não recomendados para uso na confecção de materiais cimentícios.

Pelo método acelerado das barras de argamassa, o material que apresentou maiores expansões nas amostras foi o agregado D, enquanto o que demonstrou as menores expansões foi o agregado C, sendo classificados como deletérios e inócuos respectivamente. Na Tabela 3 é possível observar um quadro resumo dos resultados obtidos pelo procedimento nas três idades de referência citadas:

Tabela 3 - Classificação da reatividade dos agregados estudados de acordo com a ASTM C 1260.

\begin{tabular}{|c|c|c|c|c|c|c|c|c|}
\hline \multicolumn{2}{|c|}{ Agregados } & A & B & $\mathrm{C}$ & $\mathrm{D}$ & $\mathrm{E}$ & $\mathrm{F}$ & REF. \\
\hline \multirow{3}{*}{ Classificação } & $\begin{array}{c}16 \\
\text { Dias }\end{array}$ & Inócuo & Inócuo & Inócuo & $\begin{array}{c}\text { Pot. } \\
\text { Deletério }\end{array}$ & Inócuo & $\begin{array}{c}\text { Pot. } \\
\text { Deletério }\end{array}$ & Inócuo \\
\hline & $\begin{array}{c}28 \\
\text { Dias }\end{array}$ & Inócuo & Inócuo & Inócuo & Deletério & $\begin{array}{c}\text { Pot. } \\
\text { Deletério }\end{array}$ & $\begin{array}{c}\text { Pot. } \\
\text { Deletério }\end{array}$ & Inócuo \\
\hline & $\begin{array}{c}60 \\
\text { Dias }\end{array}$ & $\begin{array}{c}\text { Pot. } \\
\text { Deletério }\end{array}$ & $\begin{array}{c}\text { Pot. } \\
\text { Deletério }\end{array}$ & Inócuo & Deletério & Deletério & $\begin{array}{c}\text { Pot. } \\
\text { Deletério }\end{array}$ & $\begin{array}{c}\text { Pot. } \\
\text { Deletério }\end{array}$ \\
\hline
\end{tabular}

Pela Tabela 3 é possivel observar que todos os agregados com exceção do agregado C, demonstraram variações nas suas classificações de reatividade com períodos maiores de exposição das amostras. Esse resultado indica que os produtos cimentícios podem continuar a desenvolver a reação álcali-agregado na sua microestrutura em idades avançadas quando forem utilizados materiais reativos. Isso deve ser considerado durante a escolha do agregado a ser usado, pois afeta diretamente a durabilidade do concreto resultante deste material.

Para o ensaio químico, foi realizada a determinação de sódio que a sílica ativa dos agregados consumira após 24 horas de imersão na solução de hidróxido de sódio na proporção de 1 normal por titulação da solução filtrada após o procedimento. As quantidades encontradas de perda de alcalinidade da solução para cada um dos agregados foram encontradas em relação à amostra em branco de referência para os demais materiais. Os dados obtidos podem ser observados na Tabela 4 a seguir:

Tabela 4 - Resultados obtidos com a execução do ensaio químico simples.

\begin{tabular}{c|c|c|c|c|c|c}
\hline \multicolumn{7}{c}{ Redução de Alcalinidade (mmol/l) } \\
\hline A & B & C & D & E & F & REF. \\
\hline 629,28 & 381,69 & 294,01 & 371,38 & 531,27 & 551,91 & 335,27 \\
\hline
\end{tabular}

A Tabela 4 indica que o material com menor potencial de reagir é o agregado $\mathrm{C}$, por ter consumido a menor quantidade de sódio durante o período de imersão. Esse resultado se mostra coerente com os demais apresentados anteriormente, o que pode indicar que o agregado em questão apresenta não reatividade quanto a RAA. Por outro lado, o material que consumiu maior alcalinidade durante o ensaio para reagir foi o agregado A, não apresentando relação com as classificações obtidas nos outros procedimentos para esse agregado. Outro agregado que não apresentou coerência com os demais resultados foi o agregado $\mathrm{D}$, que obteve um consumo de alcalinidade relativamente baixo quando levado em consideração que o mesmo foi classificado como o mais reativo pelo ensaio acelerado das barras de argamassa.

O Pricipio do ensaio químico simples se dá pela realção entre a redução de alcalinidade da solução com a imersão e a sílica ativa do agregado que se dissolve com a reação. Quanto maior a redução da alcalinidade da solução após o procedimento indica que o mesmo pode apresentar maiores qunatidades de sílica ativa em sua mineralogia. Porém esse não é o único fator que dita o desenvolvimento da RAA, sendo esta uma reação detentora de variáveis que influenciam em seu grau de deterioração e produtos formados. Baseado nestes fatores, deve-se considerar que muito provavelmente o método não se mostra tão eficaz ao classificar a reatividade dos agregados, devido sua simplicidade.

Para a análise das microscopias nos poros das argamassas, foi realizada a comparação das imagens obtidas com estudos anteriores para reforçar as interpretações. Em geral, os resultados obtidos a partir dessa análise se mostrou coerente com os obtidos pela a caracteização química e mineralógica dos agregados e com as classificações da reatividade dos agregados a partir do ensaio acelerado das barras de argamassa.

Os agregados A e B não apresentaram em seus poros quantidades elevadas do gel higroscópico gretado nas suas superfícies. Ambos apresentam mais de 5\% de óxido de sódio, além de quartzo e plagioclásio em suas composições (Tabela 1), estes fatores contribuem para o desenvolvimento da reação álcali-agregado, o que justifica a ocorrência de 


\section{CBPAT 2020 \\ concerss b ass \\ DE 15 A 17 DE ABRIL | FORTALEZA - CE}

gel higroscópico nos poros mesmo em quantidade reduzida. Isso mostra que os agregados não apresentam reatividade suficiente para serem considerados deletérios, resultado coerente com o observado no ensaio acelerado onde ambos são classificados como potencialmente deletérios aos 60 dias. Os poros das argamassas dos agregados A e B podem ser observados na Figura 2:

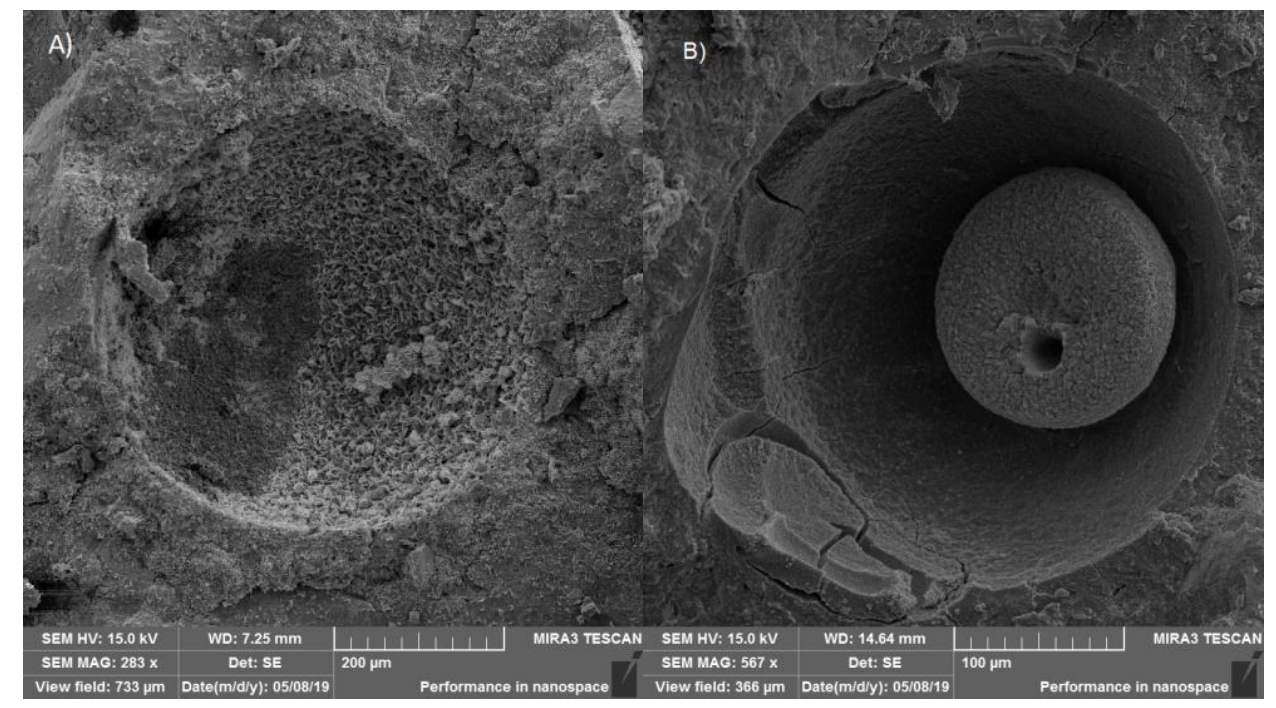

Figura 2: a) Poro da argamassa A; b) Poro da argamassa B.

A argamassa feita a partir do agregado $\mathrm{C}$ foi a que apresentou as menores quantidades dos produtos da RAA em seus poros. O agregado também apresenta mais que 5\% de óxido de sódio, quartzo e plagioclásio em sua mineralogia, acrescido do mineral periclase (Tabela 2). Isso contribuiu para o desenvolvimento do gel higroscópico nos poros da argamassa, porém o mesmo não se mostra presente em grandes quantidades na sua microestrutura, atestando a sua inocuidade. Esse comportamento é compatível com as expansões lineares observadas no ensaio acelerado, onde o agregado em questão também foi caracterizado como inócuo aos 60 dias. Na Figura 3 a seguir, pode-se observar a microestrutura da argamassa em questão:

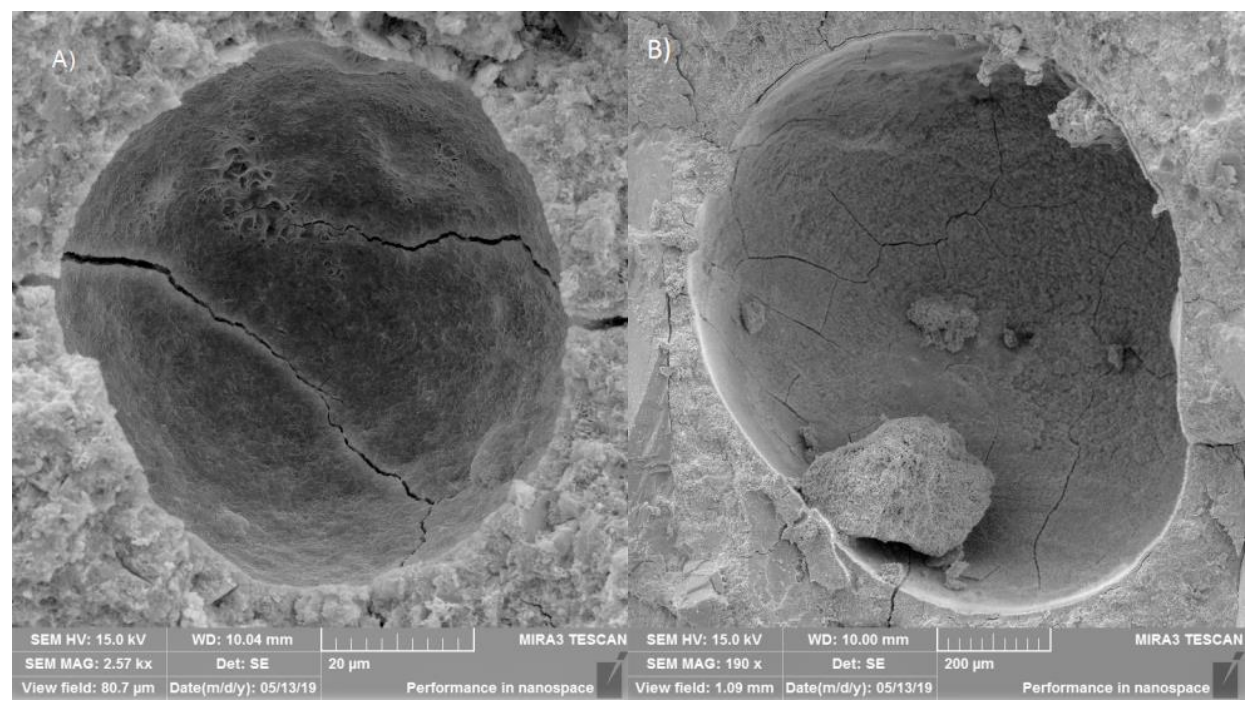

Figura 3: Poros da argamassa C.

Ao contrário das argamassas anteriores, os poros das barras contendo o agregado D possuiam as maiores quantidades de gel gretado em sua superfície, além de ter sido possível observar agregados dissolvendo devido a reação. Diferente dos agregados A, B e C, este apresenta mais de $7 \%$ de óxido de sódio, mais de $4 \%$ de óxido de cálcio e o mineral filossilicato além de plagioclásio e quartzo (Tabela 2). As grandes quantidades de sódio e sílica dos minerais do agregado certamente são a causa dos produtos formados na microestrutura da barra, sendo este um caso característico de RAA. Resultado o qual é coerente com os obtidos pelo ensaio acelerado, onde as barras feitas a partir do agregado D 


\section{CBPAT 2020 \\ concerss o ars \\ DE 15 A 17 DE ABRIL | FORTALEZA - CE}

ISBN 978-65-86819-05-2 ASSOCIAC̄AO BRASILEIRA CONSTRUÇOES

apresentaram as maiores expansões dentre as demais amostras em qualquer um dos períodos de análise. Seguem imagens dos poros da argamassa na Figura 4:

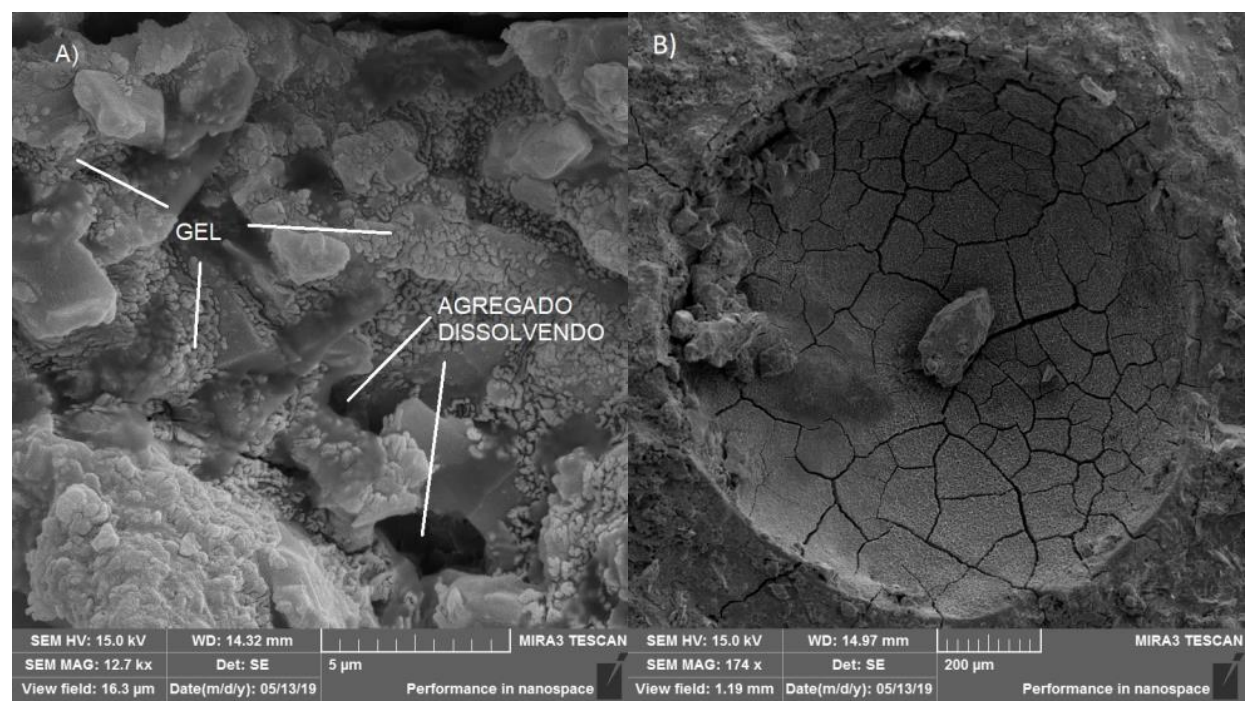

Figura 4: a) Agregado dissolvendo devido a RAA; b) Gel gretado no poro da argamassa B.

Nos poros da argamassa do agregado E foi encontrado em grandes quantidades um material cristalino em formas de pétalas, o que representa um comportamento divergente em comparação com as demais argamassas. O agregado é o que apresenta as maiores quantidades de óxido de potássio, com mais de $8 \%$ do composto químico. Outra diferença entre este material entre os demais foi o agregado apresentar feldspatos alcalinos. Mesmo com essas diferenças visíveis na Tabela 2, estes fatores também são conhecidos por potencializar as ações da reação álcali-agregado. Desse modo, os produtos encontrados na microestrutura podem ser devido manifestações da RAA, tendo em mente que as condições para o seu desenvolvimento foram constatadas. Ao levar em consideração que no ensaio acelerado a argamassa do agregado E apresentou expansões lineares maiores que $0,2 \%$ aos 60 dias, torna-se mais acertiva a interpretação que os materiais nos poros da argamssa estão ligados à reação álcali-agregado. Pode-se observar os materiais mencionados anteriormente na Figura 5 a seguir:

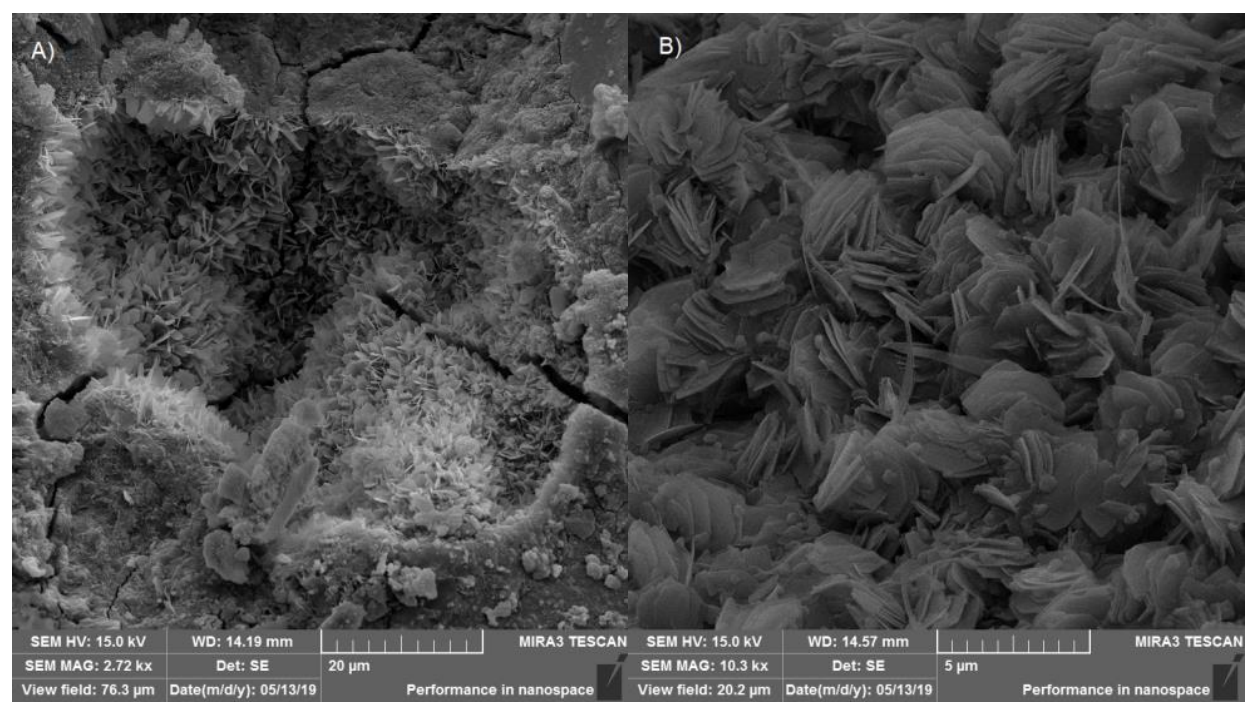

Figura 5: Poros da argamassa do agregado E.

$\mathrm{Na}$ argamassa do agregado $\mathrm{F}$ foi notado semelhanças com alguns agregados anteriores, sendo visível em seus poros agregados se dissolvendo e a formação de cristais em forma de pétala. Sua composição química é similar ao agregado D apresentando mais que $9 \%$ de óxido de cálcio, porém contando com periclase ao invés de filossilicato (Tabela 2). Não houve dificuldade na identificação de produtos na microestrutura das amostras feitas com o agregado $\mathrm{F}$, fato o qual está muito provavelmente ligado às quantidades de cálcio na composição química da areia. O ensaio acelerado confirma a 
interpretação feita com base nas expansões lineares que as barras apresentaram, classificando o agregado em deletério aos 60 dias. A seguir imagens dos poros da argamassa do agregado F na Figura 6:

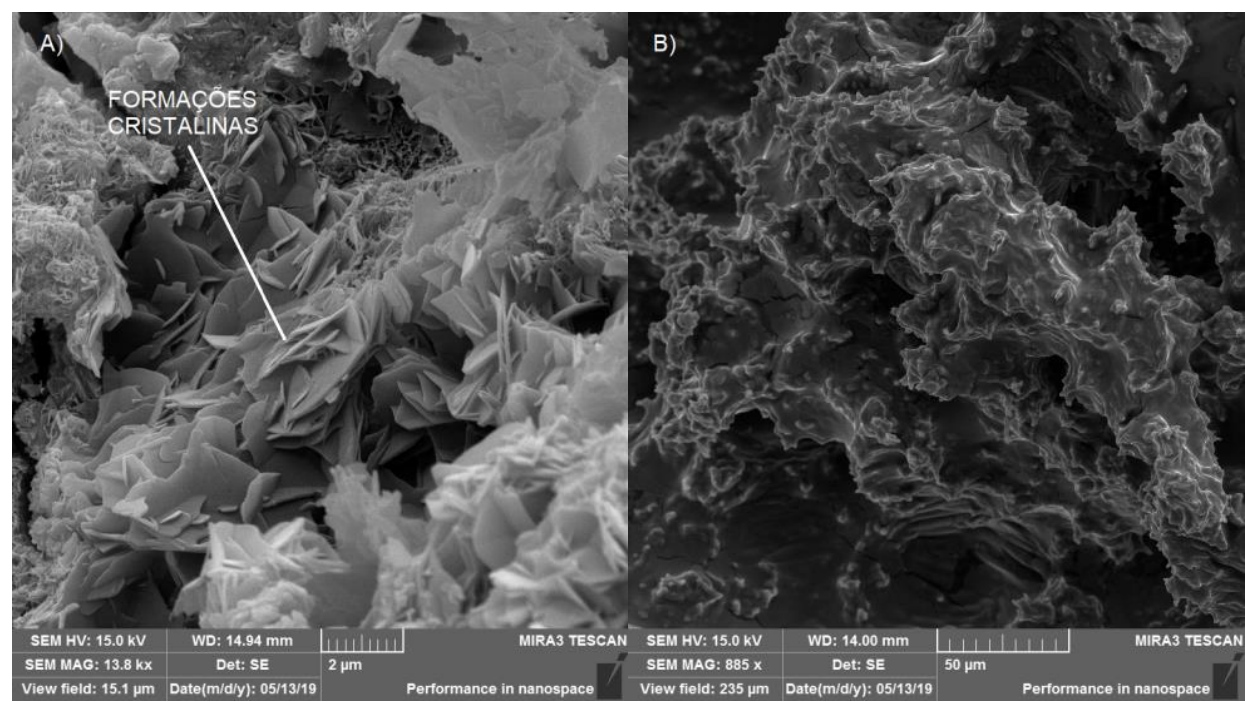

Figura 6: a) Material nos poros em forma de pétala; b) Agregado dissolvendo devido a reação.

Quanto ao agregado de Referência, não foi possível observar produtos da RAA nos poros de sua argamassa. Isso pode estar ligado ao fato que o agregado é composto por mais de $86 \%$ de sílica que provavelmente é inativa. Porém, pelo ensaio acelerado, o agregado aos 60 dias teve a classificação de potencialmente deletério. Isso indica que em idades ainda mais avançadas que o período de execução do ensaio das barras ele pode vir a apresentar as manifestações da reação álcali-agregado.

\section{CONCLUSÕES}

Pelos procedimentos e análises realizados, verificou-se que os métodos para a determinação da reatividade dos agregados se mostraram em sua maioria efetivos e de boa aplicação. O método químico simples, apesar de não indicar com exatidão a reatividade do agregado para a RAA, pode indicar que o agregado apresenta altas quantidades de sílica ativa. Como o ensaio é de rápida execução, ele se torna interessante para estudos preliminares de agregados, indicando se os mesmos precisam passar por análises mais criteriosas com procedimentos mais acertivos. O período de 60 dias para o ensaio acelerado se mostrou interessante, tendo em vista que as barras continuaram a apresentar expansões mesmo após o período de 16 dias indicado pela norma ASTM C - 1260 (2007) e de 28 dias recomendado pela literatura. Por fim, a caracterização dos poros por microscopias eletrônicas de varredura também se mostrou efetiva, sendo possível a partir delas visualizar os produtos formados na microestrutura de argamassas com agregados potencialmente reativos para a reação álcali-agregado.

\section{AGRADECIMENTOS}

São prestados os agradecimentos à UEPG pela disponibilidade de seus laboratórios e ao C-LABMU - UEPG pelos equipamentos necessários para realização dos procedimentos. Ao CNPq e Fundação Araucária pelo auxílio financeiro na forma de financiamento de projeto de pesquisa e bolsas de iniciação científica

\section{REFERÊNCIAS}

ANNUAL BOOK OF ASTM STANDARDS- American Society for Testing and Materials.

ASTM C - 289/07: Standard Test Method for Potential Alkali-Silica Reactivity of Aggregates

(Chemical Method). Philadelphia, 2007.

ASTM C - 1260/07: Standard Test Method for Potential Alkali Reactivity of Aggregates (Mortar-Bar Method). Philadelphia, 2007. 
ASSOCIAÇÃO BRASILEIRA DE NORMAS TÉCNICAS.NBR 7211 Agregado para concreto-Especificação. Rio de Janeiro: ABNT, 2009.

. NBR 7251 Agregado em estado solto - Determinação da massa unitária. Rio de Janeiro: ABNT, 1982.

NBR 9776 Agregados - Determinação da massa específica de agregados miúdos por meio do frasco Chapman. Rio de Janeiro: ABNT, 2003.

NBR NM 248 Agregados - Determinação da composição granulométrica. Rio de Janeiro: ABNT, 2003.

NBR NM 30 Agregado miúdo - Determinação da absorção de água. Rio de Janeiro: ABNT, 2001.

NBR NM 46 Agregados - Determinação do material fino que passa através da peneira 75

micrômetros, por lavagem. Rio de Janeiro: ABNT, 2003.

NBR 15577 - 4 Agregados - Reatividade álcali-agregado: Determinação da expansão em barras de argamassa pelo método acelerado. Rio de Janeiro: ABNT, 2009.

SILVA, D. J. F., FAZZAN, V., FIORITI, C. F., AKASAKI, J. L., BERNANDES, H. M. Estudo dos Efeitos do LiNO3 na Reação Álcali-Sílica e Comparação com os Efeitos da Cinza Volante na Reação. Revista de Estruturas e Materiais; Volume 3, Número 3, p. 310; setembro, 2010.

PEREIRA, E., PEREIRA, E., PIANARO, S. A., PORTELlA, K. F., BRAGANÇA, M. O. G. P., OLIVEIRA, I. C. Avaliação Das Mudanças Físicas E Mecânicas Em Argamassas De Cimento Portland Sujeitas Simultaneamente Ao Ataque Interno Por Sulfatos E Reação Álcali Agregado. Anais do $59^{\circ}$ Congresso Brasileiro do Concreto; outubro-novembro, 2017

BÉRUBÉ, M., DUCHESNE, J., DORION, J. F., RIVEST, M. Laboratory Assessment of Alkali Contribution by Aggregates to Concrete and Application to Concrete Structures Affected by Alkali-Silica Reactivity. Cement and Concrete Research; Volume 32, p. 1215-1227; agosto, 2002.

PEREIRA, F. M., NEVES, P. C. P., LENZ, D. M., VERNEY, J. C. K. Avaliação Da Reatividade Potencial De Rochas Utilizadas Como Agregados Na Construção Civil No Estado Do Rio Grande Do Sul. Rio de Janeiro: Revista Matéria; Volume 23, Número 03; 2018.

SOUZA, L., ZOLETT, E. R., CARRAZEDO, R. Estudo Dos Efeitos Do Uso Da Escória De Aciaria Na Expansão De Corpos De Prova Sujeitos À Reação Álcali-Agregado. Revista Ibracon de Estruturas e Materiais; Volume 9, Número 4, p. 572; agosto, 2016.

PEREIRA, E. Efeito Da Reação Álcali-Agregado (RAA) Associada Ao Ataque Interno Por Sulfato (ISA) Na Absorção E Porosidade De Compósito De Matriz Cimentícia. Dissertação (Mestrado) - Universidade Estadual de Ponta Grossa, 2018.

SHON, Shang-Seon. Performance-Based Approach to Evaluate Alkali-Silica Reaction Potencial Of Aggregate and Concrete Using Dilatometer Method. Tese (Doutorado) - Texas A\&M Graduation, 2008.

ROLIM, P. H. B. Reação Álcali-Agregado: Avaliação Do Método Químico De Ensaio. Dissertação (Mestrado) Universidade Federal de Santa Catarina, 2010.

BÉRUBÉ, M.; FRENETTE, J. Testing concrete for AAR in $\mathrm{NaOH}$ and $\mathrm{NaCI}$ solutions at $38^{\circ} \mathrm{C}$ aml80 ${ }^{\circ} \mathrm{C}$. Cement and Concrete Composites, Volume 16, Número 01 p. 189-198; Reino Unido, 1994.

VALDUGA, L. Reação Álcali-Agregado: Mapeamento De Agregados Reativos Do Estado De São Paulo. Dissertação (Mestrado) - Universidade Estadual de Campinas, 2002.

SILVA, C. M. Estudo Da Potencialidade De Compostos A Base De Silanos No Combate Da Reação ÁlcaliAgregado. Dissertação (Mestrado) - Universidade Federal do Rio Grande do Sul, 2009. 
MIZUMOTO, C. Investigação Da Reação Álcali-Agregado (RAA) Em Testemunhos De Concreto E Agregados Constituintes. Dissertação (Mestrado) - Faculdade de Engenharia - UNESP, Campus de Ilha Solteira, 2009.

MUNHOZ, F. A. C. Efeito de Adições Aditivas na Mitigação das Reações Álcali-Ś́lica e Álcali-Silicato. Dissertação (Mestrado) - Escola Politécnica da Universidade de São Paulo, 2007.

TIECHER, F. Reação Álacali-Agregado: Avaliação do Comportamento de Agregados do Sul do Brasil Quando se Altera o Cimento Utilizado. Dissertação (Mestrado) - Universidade Federal do Rio Grande do Sul, 2006.

HASPARYK, N. P. Investigação de Concretos Afetados Pela Reação Álcali-Agregado e Caracterização Avançada do Gel Exsudado. Tese (Doutorado) - Universidade Federal do Rio Grande do Sul, 2005.

VALDUGA, L. Influência das Condições de Ensaio da ASTM C 1260 na Verificação da Reação Álcali-Agregado. Tese (Doutorado) - Universidade Federal do Rio Grande do Sul, 2007.

SILVEIRA, A. A. Contribuição ao Estudo do Efeito da Incorporação de Cinza de Casca de Arroz em Concretos Submetidos à Reação Álcali-Agregado. Tese (Doutorado) - Universidade Federal do Rio Grande do Sul, 2007. 